\title{
:Proposal of a Supervisory System for Energy Microgeneration Case Study Granja Colombari
}

\author{
Otto, R. B. ${ }^{1-2}$, Alvarez-Ferreira, L. R. ${ }^{1-2}$, Silva, F.P. ${ }^{1-2}$, Santos, R. F. ${ }^{2}$, Nogueira, C. E. C. ${ }^{2}$, De Souza, S. N. M. ${ }^{2}$, \\ Frigo, J. P. ${ }^{3}$, Ando Junior, O. H. ${ }^{3}$ \\ ${ }^{1}$ Automation and Simulation of Electrical Systems Laboratory (Lasse) \\ Itaipu Technological Park (PTI) \\ Av. Tancredo Neves, 6731. Foz do Iguaçu - Paraná (Brazil) \\ Phone/Fax number: +55 45 3576.7200, e-mail: rodrigobueno@pti.org.br; liz.alv.fe@gmail.com \\ ${ }^{2}$ Programa de Pós-Graduação em Engenharia de Energia na Agricultura - PPGEA \\ UNIOESTE, State University of Western Paraná \\ Rua Universitária, 2069. Cascavel-PR (Brazil) \\ Phone/Fax number: +55 45 3220-3151, e-mail: cecn1@yahoo.com.br; ssouza@unioeste.br \\ ${ }^{3}$ Departament of Renewable Energies \\ UNILA, Federal University of Latin American Integration \\ Av. Sílvio Américo Sasdelli, 1842. Foz do Iguaçu-PR (Brazil) \\ Phone/Fax number: +55 45 3576-73.07, e-mail: oswaldo.junior@unila.edu.br
}

\begin{abstract}
The generating units form a distributed power generator system that uses biogas as fuel, which is produced on small farms that collect the waste from agricultural activities systems. The supervisory system of a biogas generation unit can monitor local and remote environmental, electrical and mechanical variables of the process and display this data in a user-friendly interface for analysis and decision-making. In addition to the user interface, the collected data will be stored to build the process history and analysis database that will be used as a study source and promotion of new research lines related to this topic.
\end{abstract}

\section{Key words}

Supervisory System, Biogas, Data Analysis.

\section{Introduction}

According to ANEEL 2015, Brazil has 2,945,264 kW of installed power originated from cogeneration. These rates are due to changes in the electrical system in recent years, in which distributed generation has excelled and its use has attracted the attention of independent producers connected to the system [1].

The use of biomass from waste for energy purposes has become increasingly a reality, as the generation of incomes and reductions of costs and environmental impacts [2].

However, biogas units were lacking a customized system to monitor and optimize the electro-energy performance of the process and to meet this demand, an investment is necessary for developing tools to aid in the operation and energy planning of these distributed generation systems [3].

The installation of a supervisory system in electricity generators from biogas is important in a remote monitoring system, particularly allowing the accumulation of a reliable historical data that allow its analysis, diagnose problems, and optimize the system as any future research.

The supervisory system monitors environmental, mechanical and electrical process variables and provides this data locally and remotely for stakeholder analysis, thus allowing early diagnosis of problems and assisting in decision-making in any changes that eventually occur in process patterns.

Thus, this study aimed the development of the architecture of a monitoring system and the operation of the biogas supervisory system. As for the specific objectives, this study will present the operation of the system-level user manual, the system interface developed and list the parameters monitored.

\section{State of the Art: Supervisory System Applied to Distributed Generation}

A detailed knowledge of the efficiency of a production process is an important data, therefore building an automation and monitoring of the desired elements for quantitative analysis will result in an improvement of the process [4].

The remote monitoring systems are characterized by collecting parameters without the regular presence of an 
operator. In research area, remote monitoring systems have been used in various fields of science [5].

Monitoring becomes an important tool for evaluating system reliability in power generation. The reliability could be defined as "the probability of a component, system or device performing pre-set functions under operating conditions for a period of time", and the value of reliability increases to several factors, including the degree of automation [6].

Another issue that must be observed in the monitoring and automation units is the prolonged exposure of sensors and instruments to biogas and process liquids, which inevitably leads to a degradation in performance and reliability [7].

The complexity and cost of this online monitoring depend on the number of monitored variables [8].

In the monitoring of biogas production processes, several analytical methods have been developed. Large facilities are becoming equipped with online instruments, which are able to monitor process steps either in the liquid phase or in gas phase [9].

In the process of obtaining biogas, there are several indicative factors, grouped in measurements at liquid and gaseous phases [10]. This monitoring aims to acquire information of the environmental, mechanical and electrical parameters involved in the process from the production of biomass waste to the production of biogas and electricity generation. Among the various functions of a supervisory system for distributed power generation [11]:

- Monitoring the process and all desirable variables generation system via communication cable or other means;

- Alarms windows and alarms history;

- Interface screens elaborated in a friendly way to allow a better understanding and monitoring of the process.

With the supervisory system, it is possible to monitor the most relevant parameters to each stage, enabling the formation of a database. The main parameters are:

- Effluent quality parameters: important to assess the digester performance in reducing the organic load, correlated with other data, such as $\mathrm{CH}_{4}$ and $\mathrm{H}_{2} \mathrm{~S}$ content in biogas, and biogas production according to biomass volume;

- Biogas flow: important in determining the organic load being removed from the effluent, process efficiency, correlation with the biogas production and determination of the digester retention time;

- Temperature: it is an important factor to be monitored, which can be correlated with all other variables;
- Pressure: when the digester displays pressures above $20 \mathrm{mmH}_{2} \mathrm{O}$, it means it has reached maximum biogas storage. So, the flare should be activated to relieve the pressure of the digester. However, this pressure has no influence on the quality of the gas, but it is important in controlling the volume of gas available;

- Methane: the higher the concentration of methane $\left(\mathrm{CH}_{4}\right)$ in the biogas, higher its calorific power. For applications in internal combustion engines used for power generation it is desired a gas with higher calorific value.

Therefore, this methane concentration must be monitored in order to evaluate the energy content of the biogas depending on the type of biomass:

- Measurement of biogas flow: in order to evaluate the biogas production potential in digesters and biogas consumption in internal combustion engines is required the installation of flow meters.

- Hydrogen Sulfide: it is important the monitoring of $\mathrm{H}_{2} \mathrm{~S}$ in biogas being consumed by the engine before and after the hydrogen sulfide removal system installed in the engine inlet;

- Electricity Production: besides the importance to monitor the generation parameters, the production of electricity is important to analyze the feasibility of the project;

- Water consumption: important to compare with the effluent flow that goes into the digesters.

\section{Methodology}

The method of approach used in the research is the deductive method, which defines one of the generating units as the object of the study and may extend the conclusions to other similar properties.

In relation to data collection methods, this study is based on literature review and documentary research. According to [13] the bibliographical research is the first step of any scientific research and it is developed based on material already known in the literature, reinforcing the idea that the practice emphasis is focused on problems decisions, search for answers to specific questions, performance and needs, and support decisionmaking [14].

The documentary research according [15] "is one of the most frequently used sources in research, both quantitative and qualitative," in this work it was used documents that approach Monitoring Distributed Energy Generation from Biogas.

This work is a type of case study, in which the monitoring of Granja Colombari located in São Miguel do Iguaçu-PR is the aim. The case study is the answer to questions "how" and "why", with the focus in the real context of a need that arises from the desire to understand 
certain phenomena through an investigation [16]. In this context, [17] "the essence of a case study tries to clarify a decision or set of decisions: why were taken, how were implemented and what results.

\section{A. Tools and Technologies}

The biogas monitoring system uses tools and external components, such as libraries, frameworks and Application Programming Interface (APIs). The features of each component will be discussed below.

JSON: it is a library developed in Java programming language for data processing in JavaScript Object Notation (JSON) format. Its use is widespread, and it is an alternative to the eXtensible Markup Language (XML). In the monitoring system, the JSON library is applied in coding messages to transfer data between the two applications that make up the system.

Apache Qpid: a multi-platform messaging system that uses the standard Advanced Message Queuing Protocol (AMQP), to transfer messages over the Internet. In the supervisory system, it was used in the acquisition of data and transfer information collected from the monitoring panel to the web application. For communication, the messages are encoded in JSON format.

Spring Framework: open-source framework for developing enterprise Java applications for any platform, Spring3 is a tool that provides your resources in modules such as Spring Security and Spring Data, which can be used as needed for each application. Among its main features is the Dependency Injection and Aspect-oriented Programming (AOP).

The Dependency Injection keeps a low coupling between modules of a system; it is responsible for inserting in each component its declared dependencies [18].

POA: it provides abstractions that allow the implementation of encapsulated features, so that other running objects are not changed [19].

Spring Security: it allows the access control in Java applications. Focusing on Spring Framework developed applications, Spring Security has features that support authentication and authorization processes, that means, identifying the user by validating your credentials (username and password) and provide access only to functionality in its type of access profile.

AngularJS: a JavaScript framework that follows the architecture Model-View-Controller (MVC) and provides a simple and transparent way to the user to build dynamic web applications. The structure of logical units of code is organized in order to facilitate the testing and implementation features with high reusability.

Modbus: data communication protocol used in industrial automation systems. For messaging, the Modbus uses the master-slave technique, in this way, only the master device can initiate a transaction, while peripheral devices, slaves respond to the master performing a particular task to collect and transmit information [20].

Highcharts: It is a library written in JavaScript to generate interactive graphics in vector format images on websites and web applications. In addition to web browsers for desktop, Highcharts also offers a pleasant user experience in mobile browsers, as it enables the combination of various types of graphs in only one.

\section{B. Development Architecture of Supervisory System}

The supervisory system consists of two main parts, the acquisition application and the web application. Details on the two applications, as well as the system architecture will be discussed below:

Acquisition Application: the system is in charge of getting the data provided by the collection equipment installed in the field and then transmit them to the web application. The data acquisition is performed periodically with an interval of 1 (one) minute, as default setting, as shown in Figure 1.

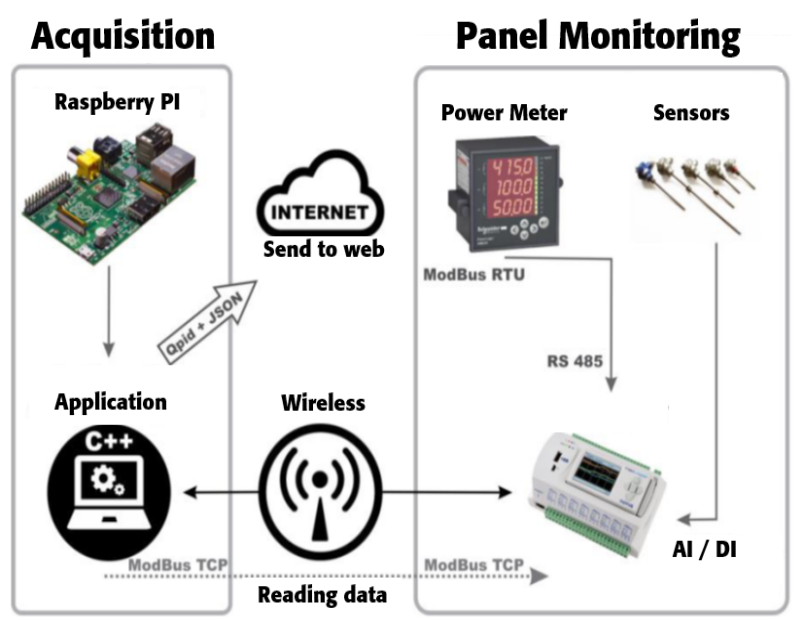

Figure 1 - Diagram from collection and sending data

In the field, the application is located in a personal computer called Raspberry PI, which has a $700 \mathrm{MHz}$ processor and $512 \mathrm{MB}$ of RAM. Developed in the programming language $\mathrm{C}++$, the application consists of two modules (ITAI, 2014):

- Reading module: via ModBus TCP protocol, it connects to the monitoring panel using a wireless network;

- Sending module: makes use of Qpid API to send information in coded form, through JSON objects to the web application.

Web application for Visualization and Monitoring of data: Responsible for presenting the data and organizing them for research and monitoring of the farm, this application follows the MVC architectural model. It divides the system responsibilities into three layers as observed in Figure 2: 
- Presentation layer: composed of visual components that define the system screens and display to users through a web browser (Google Chrome, Mozilla Firefox, etc.);

- Control layer: acts as an intermediary communication between the presentation layer and model;

- Model layer: has the transactions rules, the application data, and is responsible for communication between system and other components.

For the information storage, the monitoring system has a local database provided by the Database Management System PostgreSQL, which is widespread used regarding web applications and provides the necessary security requirements for the application.

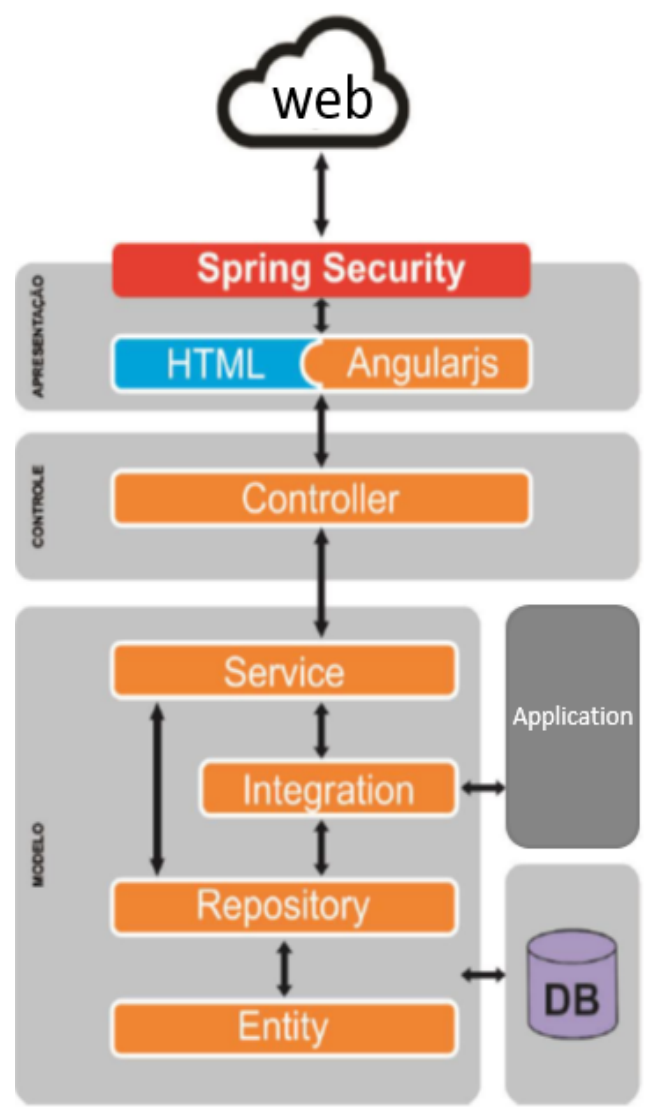

Figure 2 - Block diagram of the web application

\section{Experimental and Results}

For an analysis at first, it is necessary to define the monitored parameters, as they also serve as a basis to be used in other biogas units. Table 1 shows the parameters identified as being high influence in the biogas exploitation chain for generating electricity.

Table 1: List of instrumented parameters

\begin{tabular}{|c|l|c|c|}
\hline Process & Parameter & Units & Instrument/Sensor \\
\hline Enviroment & Temperature & ${ }^{\circ} \mathrm{C}$ & RTD Pt100 \\
\hline Biomass & Temperature & ${ }^{\circ} \mathrm{C}$ & RTD Pt100 \\
\hline
\end{tabular}

\begin{tabular}{|c|l|c|c|}
\hline \multirow{2}{*}{ Biogas } & $\begin{array}{l}\text { Water } \\
\text { Consumption }\end{array}$ & $\mathrm{m}^{3} / \mathrm{h}$ & Hydrometer \\
\hline \multirow{5}{*}{} & Flow & $\mathrm{Nm}^{3} / \mathrm{h}$ & $\begin{array}{c}\text { Thermal Dispersion } \\
\text { Transmitter }\end{array}$ \\
\cline { 2 - 4 } & Quality $-\mathrm{CH}_{4}$ & $\mathrm{oCH}_{4}$ & Gas Analyser \\
\cline { 2 - 4 } & Pressure & $\mathrm{mmH}_{2} \mathrm{O}$ & $\begin{array}{c}\text { Differential Pressure } \\
\text { Transmitter }\end{array}$ \\
\cline { 2 - 5 } Fertilizer & Pump Flow & $\mathrm{m}^{3} / \mathrm{h}$ & RTD Pt100 \\
\hline \multirow{2}{*}{ Engine } & $\begin{array}{l}\text { Operation } \\
\text { Time }\end{array}$ & $\mathrm{hours}$ & $\begin{array}{c}\text { Digital Counter } \\
\text { Relay }\end{array}$ \\
\hline \multirow{2}{*}{$\begin{array}{c}\text { Electrical } \\
\text { Energy }\end{array}$} & Generated & $\mathrm{kWh}$ & Power Meter \\
\cline { 2 - 5 } & Surplus & $\mathrm{kWh}$ & Power Meter \\
\cline { 2 - 5 } & Consumed & $\mathrm{kWh}$ & Power Meter \\
\hline
\end{tabular}

With the definition of variables, these were collected and a relationship between the data has generated secondary parameters such as biogas consumption for produced electricity, cost purchase/sale of electricity, among others.

Figure 3 shows the simplified schematic of the instrumentation for the acquisition of monitored data and presentation in the supervisory system.

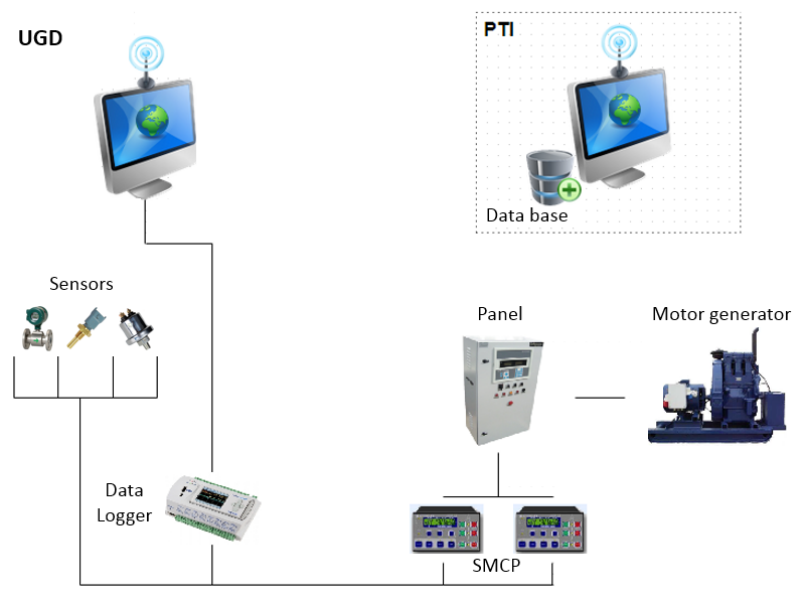

Figure 3 - Summed representation of the supervisory

The collected variables are shown in the supervisory system screen where you can check the unit details, last readings, engine consumption graph, produced energy graph (generation); pressure report, engine inlet flow and flare burning flow; monthly report - electricity (generated energy exported, energy consumed from network, balance in BRL\$) and monthly report - biogas (biogas for engine, biogas for burning flare, total biogas).

Figure 4 shows the initial screen of monitoring system. In it can be visualized the Productive Process of UG Colombari.

The farm works with the swine's growth and finishing system. The generation of waste occurs in the farms sheds, where each shed is composed of several stalls. After cleaning the stalls, the waste are sent through tubes 
for the treatment system. The system is composed by two biodigesters of tubular series flow model and semicontinuous feed. After biodigestion system's step, the effluent is sent to a decantation pond, afterwards, it is used as a biofertilizer in farms pastures. The use of biogas is made by PVC's tubes of $100 \mathrm{~mm}$ that connects the biodigester to the generator set. The electrical energy produced by the generator set aims to supply the property's internal demand, exporting the surplus to the distribution system in compensation modality. The total consumption of generator set's fuel is usually lower than the daily biogas production in the properties, leading to a pressure control in the biodigesters that avoids it to reach the pressure limits of the covers. Thus, when the biodigesters internal pressure reaches a specific value, the flare that ignites the gas is activated, relieving the pressure of the system [21].

The following items describe the main functions of the remote monitoring of Colombari Farm and its features; also they present the information that are constantly updated:

- Item 1 - Biomass: Amount of biomass produced by the animals $\left(\mathrm{m}^{3} \cdot \mathrm{d}^{-1}\right)$

- Item 2 - Burner Flow: quantity of biogas intended for burning $\left(\mathrm{m}^{3} \cdot \mathrm{h}^{-1}\right)$
- $\quad$ Item 3 - Fertilizer: amount of fertilizer extracted from treated waste $\left(\mathrm{m}^{3} \mathrm{~d}\right)$

- Item 4 - Biogas: data about production and equipment states;

○ Digester Pressure: monitors the pressure in the main digester $\left(\mathrm{mmH}_{2} \mathrm{O}\right)$;

- Methane concentration: percentage of methane inside the digester gas (\%);

- Engine Inlet Flow: consumption of biogas $\left(\mathrm{m}^{3} \cdot \mathrm{h}^{-1}\right)$.

- Item 5 - Water Consumption: Amount of water spent in the process $\left(\mathrm{m}^{3} \mathrm{~h}\right)$

- Item 6 - Date / Time Last Collection

- Item 7 - Electricity: Data on consumption and production of energy from biogas:

○ Generated Power $(\mathrm{kW})$;

○ Consumed Power $(\mathrm{kW})$;

- Exported Power: Balance between generation and consumption $(\mathrm{kW})$
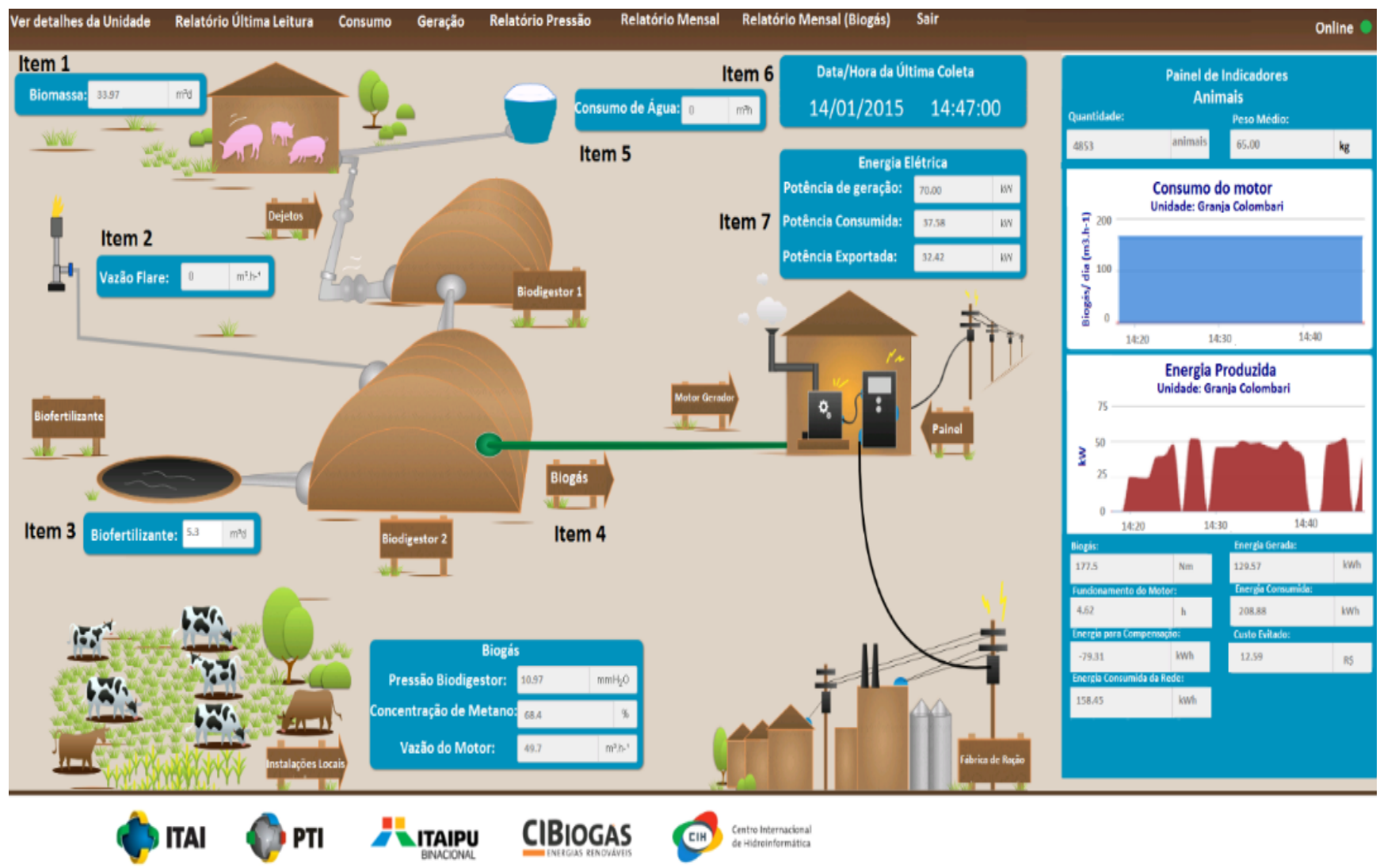

Figure 4 - Screen demonstration of the system 
Furthermore, a panel of indicators contains fields with daily values and two graphs with the values of the last thirty minutes regarding the production of biogas and energy consumption, as shown in Figure 5.

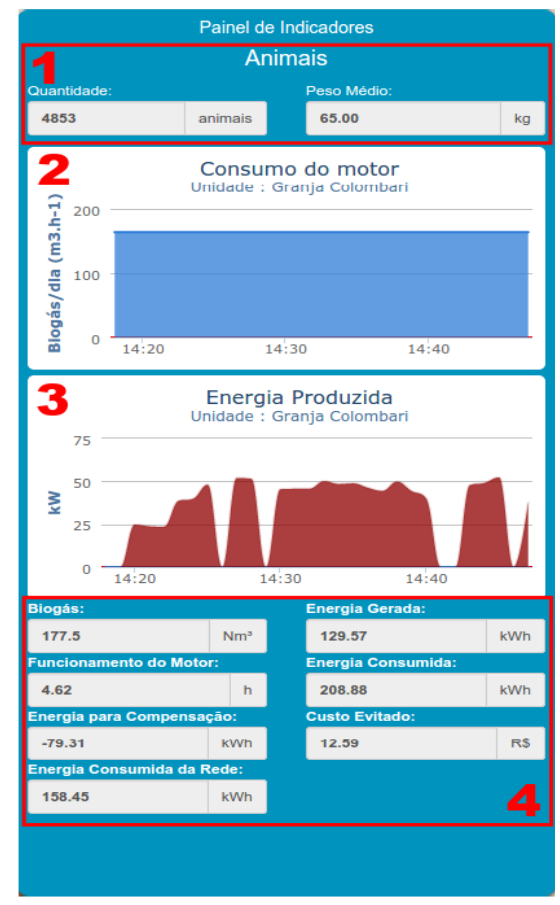

Figure 5: Panel of indicators

The highlighted items in indicators panel shown in Figure 5 are:

- Item 1 - Livestock: Data on animals:

○ Quantity (animals);

- Average Weigh: $(\mathrm{Kg})$.

- Item 2 - Graph of the past thirty minutes regarding the engine intake

- Item 3 - Graph of the last thirty minutes regarding the energy produced

- $\quad$ Item 4 - Daily updated data:

- Biogas: information on storage conditions and use of biogas $\left(\mathrm{Nm}^{3}\right)$;

- Operation Time: engine operation time (h);

- Compensation: Electric power exported to the network that will be used in compensation modality $(\mathrm{kWh})$;

- Energia Consumida da Rede: Energia elétrica utilizada da rede de distribuição da Copel (kWh);

○ Energy Generated: amount of energy being generated $(\mathrm{kWh})$;

- Avoided Cost: value in Brazilian reals of electricity consumed that was not used from the distribution network (BRL\$).

Finally, the developed tool allows obtaining management reports, as:
- Generating Unit: user accesses data on the production of biogas property. The information provided is location, responsible and contact;

- Report Last Reading: six groups of tables are loaded showing all the channels that are currently being monitored and the date/time of the last data collection;

- Consumption history: a historical graph from biogas consumption from engine and the amount of stored biogas in the property on a certain date;

- Generation History: a graph is shown with power generation for a whole day. It is possible to obtain visually the generated power information (blue) and the power that was consumed (red) for the desired period;

- Pressure Report: a table is generated with the records of the selected day and the day before presenting the pressure in the digester and biogas flow to the engine and to the burner. With this information, the user may detect problems such as gas leak, ducts blockage, defects in the digester, etc.;

- Monthly Report: displays a table with daily data calculated from the records for the selected month. With this data, the user may analyze the productivity and energy consumption generated from biogas, thus identifying if the production is worth the investment.

- Monthly Report (Biogas): shows daily registered data regarding biogas and water consumption. With this data, the user may analyze the amount of biogas produced by the property, total biogas used by the burner and the water consumption to this property.

\section{Conclusions}

The use of a supervisory system for biogas generation units is critical to the remote monitoring of a system, which is geographically distributed.

The operation of distributed generation systems is affected by the lack of information about the behavior of environmental parameters related to biogas, and the behavior of mechanical parameters, as well as the lack of preventive maintenance, which results in the need for corrective maintenance causing prolonged interruptions in electricity generation.

Prior to operation of the supervisory system, the process of collection and analysis of information was slow and laborious as it required trips to the property for observation and conducting field measurements. Not to mention the difficulty of diagnosing problems that rely on event detection at times or periods those do not become viable to have operators performing readings at the location of interest.

The remote monitoring of one or more demonstration units will serve as a management tool for viewing several variables (environmental, electrical and mechanical). In addition to viewing these variables virtually in real time (online), you can also view the entire history of past readings in various ways such as graphs, reports and 
tables. Such early diagnosis of events allow the operator to take preventive actions, in that observe changes in process operating standards.

In the case of pioneering project, it is extremely important to monitor the entire history of the process, realizing the importance of the supervision of the main variables of the process by the research institutions involved, and the generation of historical databases containing this information to allow further analysis.

The accumulation of a historical database, as much reliable as possible, proves to be more relevant in the case of demonstration units, whose performance should generate a knowledge base and must be registered in the best possible way, contributing to the Knowledge Management, thus allowing future installations in the most optimal way.

Therefore, deploy and maintain a supervisory system for distributed generation is at most importance and utility for monitoring and remote management. In addition to the monitoring tool, the system will contribute to the historical data and properly using these data may become a competitive advantage and extremely important to raise the maturity of the operating team and contribute to raising new issues for future projects.

\section{Acknowledgement}

This project is being developed for under ITAIPU for program of "Research and Development". The authors would like thank to the ITAIPU for supporting and facilities.

\section{References}

[1] ACKERMANN, T., ANDERSSON, G. SODER, L., Distributed generation: a definition. Electric Power Systems Research, 57(3), pp.195-204, 2001.

[2] TOLMASQUIM, M. T. Fontes Renováveis de Energia no Brasil. Interciência. Rio de Janeiro, RJ, p. 515, 2003.

[3] SPIER, ÉRICO B. et al. Sistema computacional integrado de operação e planejamento energético para sistemas de distribuição com presença de geração distribuída. In: XV Congresso Brasileiro de Automática. Gramado, RS: Anais do XV CBA. 2004.

[4] PRELL, A., DITL, P., KUJAN, P., SOBOTKA, M., ZAVACKY, M. Precise monitoring system for biogas engineering studies: Production enhancement by ultrasound treatment. Journal of Biotechnology, 136, Supplement(0), p.S507, 2008.

[5] LIMA, R. S. et al. Um sistema microcontrolado para o monitoramento on-line e remoto de $\mathrm{pH}$, condutividade e temperatura de águas. Química Nova, v. 34, n. 1, p. 135139, 2011.

[6] BARRETO, G. DE A. Estudo de viabilidade de um sistema de monitoramento de baixo custo para os sistemas de distribuição reticulados subterrâneos. São Paulo: Universidade de São Paulo, 2010.
[7] BRIGGS, R.; GRATTAN, K. T. V. Instrumentation control and automation in the control of biological effluent treatment. \{ISA\} Transactions, v. 31, n. 1, p. 111-123, 1992.

[8] MOLINA, F. et al. Selection of variables for on-line monitoring, diagnosis, and control of anaerobic digestion processes. Water science and technology : a journal of the International Association on Water Pollution Research, v. 60, n. 3, p. 615-22, jan. 2009.

[9] BJORKLUND, R. B. et al. Electrode specific information from voltammetric monitoring of biogas production. Talanta, v. 81, n. 4-5, p. 1578-1584, 2010.

[10] WARD, A. J., BRUNI, E., LYKKEGAARD, M. K., FEILBERG, A., ADAMSEN, A. P. S., JENSEN, A. P., POULSEN, A. K. Real time monitoring of a biogas digester with gas chromatography, near-infrared spectroscopy, and membrane-inlet mass spectrometry. Bioresource Technology, 102(5), pp.4098-4103, 2011.

[11] ZANCHET, E.. FAG. Engenharia de Controle e Automação, 2012. Available in: $<$ http://www.fag.edu.br/professores/ederson/ Informatica \%20Industrial\%20II/Sistemas\%20SCADA/Sistemas \%20SCADA\%20-\%20Apresenta\%E7\%E3o.pdf>. Acesso em: 14 Fevereiro de 2014.

[12] ITAI - Instituto de Tecnologia Aplicada e Inovação. Especificação SMCP/Projeto GD-ER e Manual de Instrumentação UGC. Foz do Iguaçu, PR: ITAI, 2011.

[13] GIL, A. C. Como elaborar projetos de pesquisa. 4. ed. São Paulo, SP: Atlas, 2002

[14] COOPER, D. R.; SCHINDLER, P. S. Métodos de pesquisa em administração. 7. ed. Porto Alegre, RS: Bookman, 2001.

[15] ROESCH, S. M. A. Projetos de estágio e de pesquisa em administração. São Paulo, SP: Atlas, 2006.

[16] YIN, R. K. Case study research: design and methods. 2. ed. ed. Sage: Thousand Oaks, 1994.

[17] SCHRAMM, S. Notes on case studies of instructional media projects. Washington, DC: Working paper, the Academy for Educational Development, 1971.

[18] CARVALHO. Spring Framework: Introdução. Available in: $\quad<$ http://imasters.com.br/artigo/4497/java/springframework-introducao/>. Acesso em: 10 de Janeiro de 2015.

[19] RAINONE, F. Programação Orientada a Aspectos Dinâmicos, $2005 . \quad$ Available in: $<$ https://www.ime.usp.br/ leliane/MAC5701/2005oSem/PlanosMonografias /Flavia.pdf $>$. Acesso em: 10 de janeiro de 2015.

[20] SOUZA, V. A. O Protocolo modbus. Available in: < http://www.cerne-tec.com.br/Modbus.pdf $>$ Acesso: $11 \mathrm{de}$ janeiro de 2015.

[21] SILVA, F. P. Eficiência energética de uma unidade de microgeração de energia elétrica a partir do biogás da suinocultura. pp.17-20. Cascavel-PR. Março, 2015. 